\title{
Triple Helix Collaboration in Indonesia's Covid-19 Vaccine Development: Understanding The Barriers and Enablers
}

\author{
D.A., Jatraningrum', R.K. Jati, S. Maludin, R. Manalu, R.L. Helmi, and W. Hermawati \\ Directorate for Research, Technology and Innovation Policy Formulation
}

\begin{tabular}{|c|c|}
\hline ARTICLE INFO & ABSTRACT \\
\hline Article History: & \multirow{7}{*}{$\begin{array}{l}\text { The development of the Covid-19 vaccine (nationally named Merah } \\
\text { Putih Vaccine) is a national innovation activity initiated by the } \\
\text { Indonesian central government and coordinated by the National } \\
\text { Research and Innovation Agency. This study aims to understand } \\
\text { the collaboration between the triple helix components (Industry, } \\
\text { Academician, and Government) in the Merah Putih vaccine (MP } \\
\text { vaccine). An exploratory study of the actors involved in developing } \\
\text { the MP vaccine was carried out through a primary data collection } \\
\text { process from January to August } 2021 \text {. Furthermore, a descriptive } \\
\text { analysis of triple helix collaboration discloses components, } \\
\text { functions, and configuration in the MP vaccine development. Our } \\
\text { finding reveals that the most highlighted issue is the reputation } \\
\text { concerning two significant dimensions; scientists' experience or } \\
\text { R\&D human resources on real-life projects and the R\&D facilities } \\
\text { and infrastructure. However, neither of the dimensions can } \\
\text { accelerate the proof-of-concept vaccine candidate immediately. } \\
\text { The critical findings of this research serve as empirical evidence of } \\
\text { the barriers and enablers of a national innovation project initiated } \\
\text { by the government, as seen from the triple helix collaboration with } \\
\text { the emerging issues approach. }\end{array}$} \\
\hline Received : 07 November 2021 & \\
\hline Revised : 17 November 2021 & \\
\hline Accepted : 18 November 2021 & \\
\hline Available online : 15 December 2021 & \\
\hline $\begin{array}{l}\text { Authorship Contribution: } \\
\text { All authors have equal contribution } \\
\text { as the main contributors. }\end{array}$ & \\
\hline $\begin{array}{l}\text { Keywords: } \\
\text { Triple Helix Collabo } \\
\text { Covid-19, } \\
\text { Emerging Issue, } \\
\text { Vaccine }\end{array}$ & \\
\hline
\end{tabular}

\section{INTRODUCTION}

Through Presidential Decree (KEPPRES) Number 18 of 2020 concerning the National Team for Accelerating the Development of the Corona Virus Disease 2019 (Covid-19) Vaccine, the Indonesian government initiated national innovation activities through research and development of local Covid-19 vaccines. This initiative involves

* Corresponding Author. +62-811-31-8210

E-mail: diah.anggraeni.jatraningrum@brin.go.id universities, government research institutions, and the pharmaceutical industry known as the Covid-19 Vaccine Development Team. In the context of the science, technology, and innovation (STI) policy, this vaccine development collaboration is called the triple helix collaboration (Konstantinovich et al., 2021). Referring to the Presidential Decree, the Covid-19 vaccine was developed, then labeled as the Merah Putih Vaccine (note: Merah Putih refers to two colors of Indonesia's flag). The government encourages this activity 
to fulfill the massive demand for vaccines due to the enormous population, encourage vaccine independence, reduce import dependence, and save costs in providing vaccines for the national vaccination program, particularly during this pandemic. In terms of track record, neither universities nor government research institutions have successfully researched and developed candidate vaccines and meet Indonesia's proof-of-concept criteria (Nurhakim, 2021).

Developing a vaccine requires a long time, a complex process, a high risk, and a significant and long-term investment return (Lurie et al., 2020). In general, the success rate of developing a seed vaccine into a vaccine is low. Its success rate is highly dependent on the synergy and collaboration of many stakeholders, particularly in finance, human resources, infrastructure, materials, equipment, and other supporting policies. At least, a university or an R\&D institution and the vaccine industry collaborate to research and develop a vaccine candidate, testing and ensuring the human vaccine safety and efficacy (Rappuoli \& Hanon, 2018). Funding is a critical factor in the research and development of an immunization candidate. Due to the high risk of failure during preclinical trials and clinical trials, it is necessary to have a well-targeted and sustainable financial management strategy. Until now, no institution has been able to complete all stages of developing a vaccine candidate until it is ready for production and use by the public (Druedahl et al., 2021). International cooperation is needed to produce vaccines to reduce costs so that they are affordable and make it easier to distribute them evenly throughout the world (Guimón \& Narula, 2020). Densely populated countries, such as China, India, the United States, and Russia place molecular biology research at the forefront of research centers on vaccine development and receive full support from their governments, either through policy, finance, human resources, international cooperation, even investment in facilities and infrastructure that requires significant capital (Bloom et al., 2021). As a densely populated country, Indonesia faced lagging in applying innovative models, including the health sector. Indonesia's high dependence on developed industrial countries has caused molecular biology research challenges in creating a proof-of-concept vaccine candidate to be produced by a vaccine industry, as also mentioned by (Lurie et al., 2020).

Since the Pasteur revolution, Indonesia has had a national vaccine industry in molecular biology as a region prone to infectious diseases. During the Dutch East Indies reign, since 1890, this national vaccine industry was established. Research and development of vaccines were carried out jointly by R\&D institutions at that time. Due to the enormous changes in world health regulations regarding vaccines, the national vaccine industry faces challenges mastering technology in inventing vaccine seeds and developing them into proof-of-concept vaccine candidates. With that situation, none of the R\&D activities done by research institutions and universities were able to produce seed vaccines in Indonesia until the pandemic Covid-19 spread worldwide.

Unlike other countries, Indonesia is more focused on maintaining the availability of vaccines in the country. The existing national vaccine company focuses on the production, marketing, and distribution of vaccines to meet national and international needs. Its production facility is one of the best globally, with a capacity of 3,200 million doses per annum (Bio Farma, 2019). Although the national vaccine industry, universities, and government research institutions collaborate in research and development, none of the vaccines produced by the industry-university and $R \& D$ institution partnership resulted in a proof of concept-seed vaccine. Alternatively, global R\&D institutions or universities, various vaccines have licensed the vaccine to the national vaccine company. The global $R \& D$ institutions, biotech start-ups, and technology transfer office syndications have developed the vaccine technology transfer that meets the criteria of proofof-concept in a well-established technological and financial system support. In response to the rapid spread of Covid-19, the national vaccine company focuses on packaging and distributing vaccines through imported supplies from various imported vaccine manufacturers from China, the United Kingdom, the United States, and several other countries through the COVAX facility (Bio Farma, 2021). 
Vaccines are a must to develop, both in the pandemic paradigm and the future standard paradigm. Scientists develop vaccines during a pandemic concurrently and at certain stages. The risk of failure is much higher, especially in vaccine seeds. In the traditional stage, a proofof-concept vaccine candidate is one gateway to proceed with clinical trials. However, during the pandemic, the vaccine seeds can proceed to pilot production units in the vaccine industry for scaleup, clinical trial materials, and process validation. While the manufacturer pilot carries out production, the developer must accomplish and publish preclinical testing. To overcome preclinical trial failure, vaccine candidate developers usually already have platforms that have been tested for years and have experience even with new types of viruses (Lurie et al., 2020).

The national vaccine development, initiated through the national research and innovation agency, is carried out starting from the upstream process through a collaboration scheme with universities or government research institutions as the vaccine industry partners in providing the proof of concept vaccine candidates. We observed that all Covid-19 vaccines currently used result from research and development by global biotech companies collaborating with the vaccine industry.

Compared with other countries, the process of making the MP vaccine in Indonesia faces several constraints, including a lack of availability of funding, facilities, human resources, and solid international networking. Moreover, due to none of those global biotech companies operating in Indonesia, initiating innovation by the government to produce the MP vaccines are undoubtedly the right step because Indonesia will benefit from mastery of vaccine technology. Despite a lack of experience and national track record in mastering vaccine technology, the vaccine development effort aims to deal with the current Covid-19 virus, transmit it domestically, and anticipate future pandemics. Currently, there are at least five universities and two government research institutions that are actively developing vaccines, both the traditional approach (inactivated virus and protein subunit) and the novel vaccine approach (DNA, RNA, viral vector) and virus-like particle.
The government also facilitates universities and $\mathrm{R} \& \mathrm{D}$ institutions to collaborate on the triple helix concept with the national pharmaceutical industry as an academic-industrial partnership.

The main objective of this research is to understand the current status of the collaboration among the actors/components, relationships, and its configuration in the MP vaccine development. Moreover, we also identified barriers and enablers of triple helix collaboration through an emerging issues approach. This exploratory study provides the experience of how the innovation model established through the triple helix model during the pandemic is considered precious knowledge and still lacking in Indonesia. In order to maintain its sustainability, we present the policy implication of this collaboration.

\section{ANALYTICAL FRAMEWORK}

Many scholars have widely applied Triple Helix's collaborative research. Apart from being an integral policy making tool for increasing innovation and promoting economic development (Etzkowitz \& Leydesdorff, 1997), measuring the role and interaction of research at universities or other R\&D institutions with industry, as well as the interaction of government policies in developing a knowledge-based economy (Etzkowitz, 2008) and policy makers in contexts other than innovation (Saad \& Zawdie, 2011). Innovation policy and practice researches apply triple helix collaboration in many countries or regions to analyze innovation policies and policy recommendations, such as in the Nordic countries (Solesvik, 2017), Germany (Kreusel et al., 2018), Japan (Yoda \& Kuwashima, 2020), South Korea (Yoon \& Park, 2017), India (Kumari \& Mallick, 2017), China (C. Liu \& Cai, 2018). Triple helix collaboration consists of three main aspects: components, relationships between components, and system functions. The essential components consist of the institutional scope of universities, industry, and government. Although most innovative approaches consider the firm or industry sector a critical element in innovation analysis, they also recognize the vital role, interaction, and collaboration of the triple helix in driving 
innovation (Etzkowitz \& Zhou, 2018; Leydesdorff, 2000).

Etzkowitz \& Leydesdorff, (2000) distinguish three configurations in the triple helix collaboration: the statist, laissez-faire, and balanced model. First, the government plays a significant role in the statistical configuration, encouraging research and development collaboration with academia and industry and limiting their capacity to initiate and develop innovative transformations. This configuration occurs in some developing countries, such as Russia, China, and Latin American and Eastern European countries. This configuration may change over time, as in China (Cai \& Liu, 2015). Second, the nature of the laissez-faire configuration is limited state intervention in the economy. This configuration is typical in developed countries, such as the United States and some Western European countries. The industry as a driving force and the other two fields act as additional support structures with a limited role in innovation - academics in universities act primarily as providers of skilled human resources and governments primarily as regulators of social and economic mechanisms. Third, the balanced configuration is a particular form for the transition to a higher knowledge society, where universities and other knowledge institutions containing academics in universities act in partnership with industry and government and even lead in joint initiatives. Several regions or new industrial centers in developed countries, technology, and innovation-based economics, usually apply the balanced configuration (Ranga \& Etzkowitz, 2013). This balanced configuration is the ideal triple helix collaboration. It is scarce because of the many factors that influence it, mainly due to factors of different institutional logic between universities - industry - government (Cai \& Etzkowitz, 2020).

The actors in the regional and national innovation systems interact with each other in a helix manner. However, each triple helix actor also cooperates with triple helix actors in other regions and countries with the same consensus understanding of triple helix collaboration. The intersection of collaboration can be between national industry - foreign universities, domestic universities - foreign industry, government - for- eign industry, or other helix slices by consensus to carry out innovation initiatives. The dimensions of globalization as depicted in Figure 1 regarding the transnational triple helix model, where there is a dimension of globalization in the middle of the transnational triple helix model framework. There is a transnational helix space (Cai et al., 2019), as shown in Figure 1. The goal is to carry out more comprehensive collaboration because in developing countries, sometimes the logic of institutions does not support or benefit innovation initiatives from one helix in a region or country (Cai, 2013).

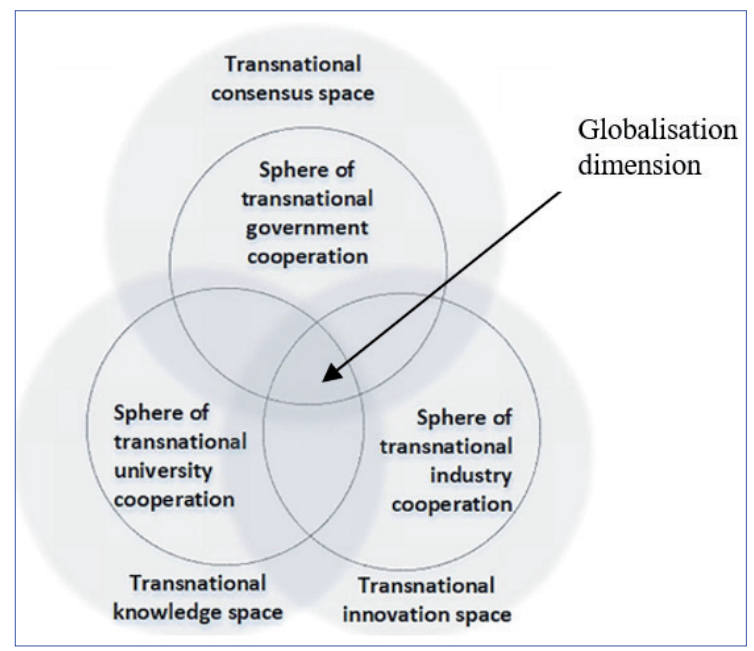

Source: Cai (2013)

Figure 1. Transnational triple helix model

Universities have a role in innovation in a knowledge-based society (Etzkowitz \& Leydesdorff, 2000). Universities play a role in 'knowledge capitalization' by organizing the technology transfer to existing companies or creating new companies to realize their traditional role in technology transfer Etzkowitz (2008). says universities are the core helix that replaces industry and government as innovation providers in some circumstances. Technology transfer and networking are the main reasons for establishing synergy in the triple helix collaboration. In science, synergies can mean the availability of new options due to cross-border collaboration (across disciplinary, sectoral or geographic), increasing the options in the system under study by making the difference even further (Leydesdorff, 2018). 
The triple helix collaboration for innovation will create barriers and enablers (Razak \& White, 2015). There are several empirical studies on the barriers and challenges faced by institutions in triple helix collaboration. The study on barriers and challenges in developing countries consists of three essential issues; (1) relationship issues: including institutional logic, work culture, and organizational goals; (2) reputation issues, especially on the perception of the capacity and capability of universities in specific fields of science and technology that affect the innovation targets; and (3) government policy issues.

To make it easier to understand the helix's identification, we use the term A-B-G, where A is for the academic component, B is for industry, and $G$ is for the government (Schramm, 2017). Figure 2 highlights role and functions of each helix which we extracted from various literature. Academics have duties and roles as education and training (Conceicao \& Heitor, 1999), research and development (Slaughter \& Rhoades, 1996), business incubator (Mian, 1996), and spin-off and start-up enterprises (Veselá \& Klimová, 2014). The industry has duties and roles as entrepreneurial venturing (Knudson et al., 2004), capitalization of knowledge (Viale, 2013), production and value-added (Szeinbach et al., 1997), commercialization of product (Yang \& Chang, 2010), and product life cycle (Allanson \& Montagna, 2005). Meanwhile, the government has duties and roles in policy formulation (James \& Jorgensen, 2009), national development program (Chung, 2013), infrastructure (Detmer, 2003), and safety and security of investment (Monsreal-Barrera et al., 2020). Translational knowledge commonly occurs between academia and industry in technology transfer, real-life research and development projects, and human resource internships (Hishida Koichi, 2013). Translational information from academics to government on curriculum policy, educational standards, and funding (Collins, 1998). The government's translational policy towards industry includes incentives and financing, industrial strategy, and advisory services (O’Sullivan et al., 2013).

To contribute empirical evidence in the form of primary data from the field on barriers and enablers as the purpose of this study, we analyzed several universities, government research institutes, the vaccine industry, and national research and innovation bodies as components involved in the initiation of vaccine innovation. National teams in vaccine research and development and represents each helix according to a pre-designed issue. Empirical data were collected through semi-structured interviews and focus group discussions with representatives of the actors' institutions.

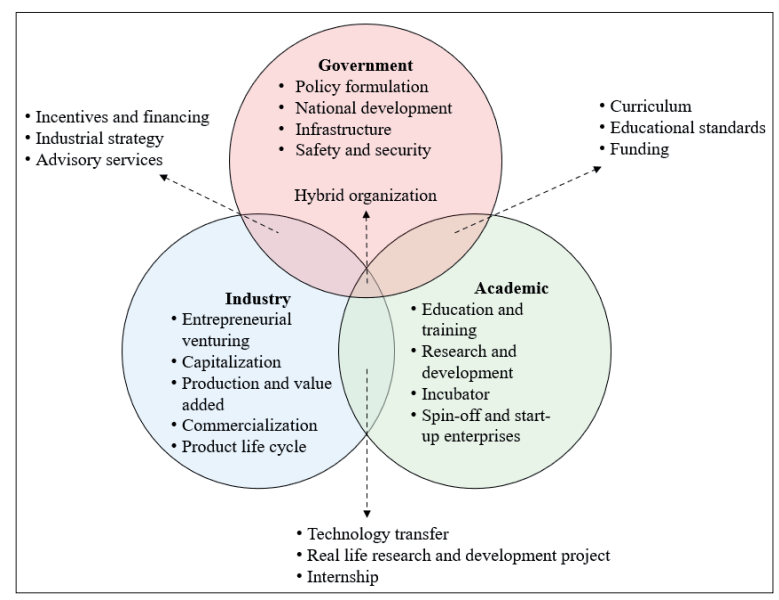

Source: constructed by the author

Figure 2. Role and function of the element within AB-G triple helix collaboration

\section{METHODOLOGY}

\section{A. Data collection}

Based on the results of initial data collection from vaccine development actors, in this study, we selected seven institutions that represent the triple helix, namely; 2 public universities, 1 government research institute in the field of molecular biology research, 2 state-owned vaccine company, 1 private vaccine company, 1 government agency in the field of national research and innovation, and 1 government institution in drug and food control. The national research and innovation agency represents the central government as the holder of the presidential mandate to coordinate vaccine development nationally and facilitate funding for collaborative research and development of Covid-19 vaccines. The food and drug agency is the regulator that initiates assistance and supervision in fulfilling the regulatory rules for vaccine registration as part of the investigational new 
drug (IND) process. We collected the data from January to August 2021. There are three important reasons for choosing the seven institutions: (1) fulfill the academic - industry-government triple helix collaboration elements (Leydesdorff, 2000), (2) have the same goal in product commercialization (Yang \& Chang, 2010), and (3) there are activities to do together (Hishida Koichi, 2013).

The standard of collecting qualitative data through semi-structured interviews and focus group discussions adopts several essential points; (1) the development of discussion content categories is independent for each participating institution representing its organization, (2) aims to get consensus for each session, (3) coding some content that is the same but in different ways of communication, (4) conducts reliability assessments between researchers and identify unreliable categories for revision, and (5) Repeat the inter-researcher reliability assessment after revision (Moretti et al., 2011). Revision is done by direct confirmation to each actor and informant, with every content often repeated (Moretti et al., 2011). In actual conditions, each helix has carried out activities according to their respective processes, which have a 'theory basis', although with a different delivery. In organizational research literacy, what is conveyed by the academic community between the triple helix is an amalgamation of theory and reality (Langley, 1999). This research is a case study in developing a Covid-19 vaccine seen from various actors representing the triple helix. Although the case study looks singular, 'Covid-19 vaccine development', there are many case studies from seven different institutions or agencies. Therefore, we used a methodological approach consisting of multiple case studies (Eisenhardt \& Graebner, 2007) and content analysis (Krippendorff, 1989). In-depth interviews with key actors are suitable for providing insight into the mechanisms of vaccine development; the wealth of insights goes beyond what can be extracted solely from quantitative approach documentary data (Collinson \& Liu, 2019). In addition, we applied content analysis to examine regulatory and policy documents and triangulated them with primary interview data (Krippendorff, 1989). Combining primary and secondary data facilitates our research efforts to increase the reliability of our data analysis. It also engenders a subtle and nuanced understanding of vaccine development and the interactive process between relevant stakeholders captured by the triple helix model of innovation (Jørgensen, 2004).

The purpose of collecting primary data directly from the field is to analyze the key actors considered essential to represent each helix component on a pre-designed topic. To obtain preliminary research data, we conducted an exploratory study of institutions that will provide information through a series of semi-structured interviews and focus group discussions. The institutions fit the context of the triple helix collaboration in developing the MP vaccine. We developed the coding of some content within the scope of work on the early-stage development of the MP Vaccine under the pandemic paradigm (Lurie et al., 2020). We chose an institution from the composition of the national team, better known as the Merah Putih Vaccine Development according to the Decree of the Chairman of BRIN Number $167 \mathrm{M} / \mathrm{KPT} / 2020$ and consecutive related decrees concerning the national Team for Accelerating the Development of the Corona Virus Disease 2019 (Covid-19) Vaccine. Of the Covid-19 Vaccine Development Team members, we initially selected 3 institutions representing key helix components, namely the national institute of bio-molecular research, a state-owned vaccine company, and the national research and innovation agency. However, during semi-structured interviews and focus group discussions with these institutions or agencies, different institutions or other vital bodies resulted in a snowballing of data collection. The team concluded from 12 interviews with key stakeholders and informants that seven key stakeholders play a significant role in vaccine development. The strong relationship between the actors demonstrates the importance of information. The addition of these institutions or agencies enriches the empirical field data for this research. The institution or agency also represents the components of the triple helix collaboration, which consists of a public university that is very active in research and development of the MP vaccine, a private-owned vaccine company that is a partner of the public university, and a national 
food and drug agency that actively assists the academic-industry collaboration.

\section{B. Data analysis}

In the context of the triple helix model of innovation, descriptive data represents institutions or agencies, collaboration within institutions or agencies' networks, and the interrelationship of duties and responsibilities presented as in the MP Vaccine Development. All information that is interrelated in the triple helix collaboration, if explored simultaneously, will provide disconnected information to describe the barriers and enablers in the ongoing triple helix collaboration. The depiction of barriers refers to the emerging issues approach (Razak \& White, 2015). Analysis of the role and function of each helix and combined with the A-B-G collaboration will provide a general picture of the triple helix collaboration in Covid-19 Vaccine development. Roles and functions are the daily internal tasks of the institution or agency.

In contrast, the institution must collaborate due to the dependence on input-output from the respective institution or agency. We constructed a descriptive analysis based on the theory and elaborated data triangulation with documents, archives, and observed technical objects to provide recommendations on the sustainability of the innovation initiation of many products that can drive a knowledge-based economy (Etzkowitz, 2008).

\section{RESULTS AND DISCUSSION}

\section{A. The triple helix collaboration of the MP vaccine development: The institutional roles}

Figure 3. displays the triple helix collaboration of the seven institutions or actors in MP vaccine development. In the A-helix component, we have observed the national institute of bio-molecular research and the public university. First, the national institute of bio-molecular research is a government-owned research institution under the coordination of the national research and innovation agency. This institution has conducted research and laboratory-scale testing to obtain antigen proteins and vaccine seeds using a recombinant protein platform. The antigen is immunologically tested and then published scientifically as vaccine candidates. The source of funding for MP vaccine research comes from the state budget. Second, the primary public university (public university-1) conducts research laboratory-scale testing to obtain protein antigen and vaccine seed, together with the other university (public university-2), proceeds the preclinical trial phase-2, using primate, Macaca. The two public universities collaborate by bringing experience in developing new medicines for humans and vaccines for animals and livestock. The private collaborator accommodates the university the full financial support and lab facilities to its vaccine research and development, and we observe that, based on the progress of the vaccine development process, the partnership between the university and the private-owned vaccine company seems to be more limber and independent than the national bio-molecular research-state-owned vaccine company partnership. As an educational institute and deliver research outputs, a public university can play vital roles in innovation capacity; as an innovator, incubator, and even a spin-off start-up enterprise.

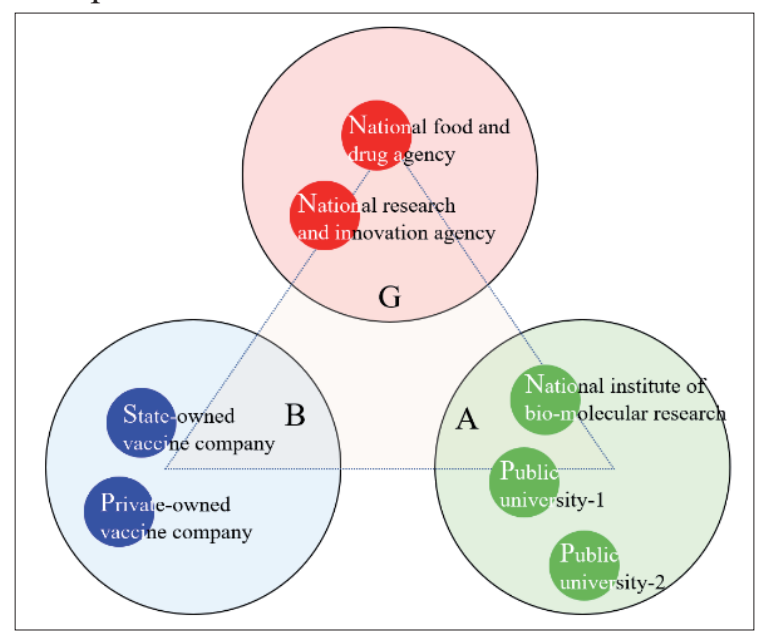

Figure 3. The Triple Helix Collaboration: Analysis of The seven institutes in MP Vaccine development

The B-helix consists of a state-owned vaccine company and a private-owned vaccine company. First, the state-owned vaccine company. All vaccines and other pharmaceutical products are knowledge-based products (KBP), and the 
industry itself performs a knowledge-intensive industry (KBI) (Contractor \& Lorange, 2002). To produce vaccines, the state-owned vaccine company transfers vaccine technology from many global vaccines research and development institutions, including technology transfer syndications from global institutions in providing and distributing vaccines globally. In the triple helix context, the state-owned vaccine company's role as a development partner; in testing, scaling up prior to the vaccine manufacturing process, while the national institute of bio-molecular research provides vaccine seeds. To secure the national vaccine stock, apart from imported vaccines, the state-owned vaccine company cannot entirely rely on the national institute of bio-molecular research to produce vaccine seeds that meet the proof of concept criteria. They take another collaborative option to produce vaccines domestically, wherein a foreign university licenses the seed vaccine, which is termed "the state-owned vaccine" or "half-MP vaccine." Even the foreign universities have completed the preclinical test passage published by WHO earlier this year. It indicates that our national research institute is not ready to fulfill the Covid-19 seed vaccine demand in the short term, so the company catches up with the opportunity through a global collaboration strategy. The highest goal of this state-owned vaccine company is to produce national Covid-19 vaccines, according to the GMP standards set by WHO. In principle, the production activities designed by this company carry out an 'end to end process, which is different from packaging imported vaccines and distributing Covid-19 vaccines through the COVAX facility currently applied in Indonesia. Second, the private-owned vaccine companies, a foreign investment company, collaborate with the public university partner to test various Covid-19 vaccine candidates. Recently, the company fully supported the accomplishment of preclinical test phase I, phase II, and challenging test over the Delta variant. It also provides BSL3, Animal BSL3, vaccine manufacture line, and GMP/CPOB certified, whereas the products on the market have not been registered in the circulation test by the national food and drug agency. Although this company is a newcomer to the national vaccine industry, as an established company brand holder, the company has a vast network and collaboration with global partners, both in scientific, technical and financial-economic supports. However, the network can be an advantage that may accelerate the development of the MP vaccine for the privately-owned company and public university collaboration.

G-helix consists of the national research and innovation agency and the national food and drug agency. First, the national research and innovation agency is a government institution that carries out the president's mandate as the team leader in developing the Covid-19 vaccine through facilitating funding, lab facilities and infrastructures, policies, and assignment of the daily implementation team. Second, the national food and drug agency is a government institution that supervises compliance with regulations on the research and development of MP vaccines. The national food and drug agency assists in the process of fulfilling the requirements of Good Laboratory Practice (GLP), Good Clinical Test Practice (GCP), Good Manufacturing Practice (GMP), Investigational New Drug (IND), and the release of Emergency Use Authorization (EUA).

\section{B. The collaboration between the national institute of bio-molecular research and the state-owned vaccine company}

First, the national institute of bio-molecular research is a government-owned research institution leading molecular biology-related research in Indonesia. In the triple helix, the government research institute represents the academic component. Second, The state-owned Vaccine company is a national company that focuses on the demand for quality and affordable national and global-distributed vaccines under WHO standards. The vaccine company is a worldclass vaccine manufacturer with experience and WHO pre-qualification for various vaccines and other biological products. In the triple helix, the state-owned vaccine company represents an industry component or helix, which has also played an active role in developing vaccine research collaborations with various national and 
global research institutions/universities. Thus, the state-owned vaccine company plays beyond the vaccines' manufacturer's role and is part of the world's biotech experts and global vaccine network by implementing R\&D-driven based partnerships with academic institutes. Since 2011 the state-owned vaccine industry has established the National Vaccine Research Forum (FRVN). In the molecular biology-based new drug, R\&D is the basis of new product development. The initial research stage provides an assessment of the pattern of the targeted disease. Identification of molecules/antigens as vaccine candidates and methods for producing/purifying antigens are critical in further product development. It is also essential to designate historical information on vaccine seeds and antigens as documented raw materials. The research's output is the validation of a proof of concept's vaccine candidates. The third, the national research and innovation agency, represents the government's role, which carries out the president's mandate as the National Covid-19 Vaccine Development Team. Furthermore, the chairman of the agency establishes the national Covid-19 vaccine implementation team.

Figure 4 shows the collaborative development of the Covid-19 vaccine between national biomolecular research institutions and state-owned vaccine companies. The national bio-molecular research institute developed the vaccine platform as a protein subunit derived from viral proteins referred to as 'spike' and 'nucleocapsid.', which are domestically transmitted. The former Ministry of Research and Technology/National, Research and Innovation Agency's policy emphasizes that the MP vaccine must be isolated from viruses transmitted in Indonesian territory, developed in Indonesia, and produced by Indonesian pharmaceutical companies. Thus, national biomolecular research institutes and state-owned vaccines isolated a locally transmitted virus and proceeded the pandemic paradigm in developing the MP vaccine as Lurie et al. (2020). After the targeted protein antigens with the appropriate yield met the criteria, they continued to process the phase 1 and 2 preclinical prior to commercial scale to provide larger quantities of material prior to clinical trials.

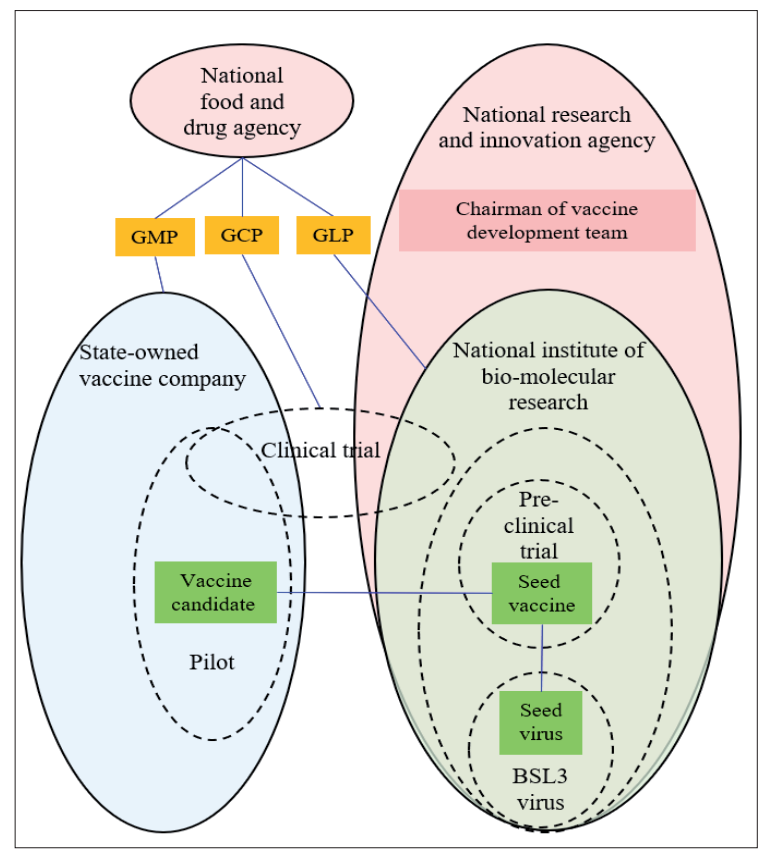

Figure 4. The triple helix collaboration in Covid-19 vaccine development between the national institute of bio-molecular research and the state-owned vaccine company

\section{The collaboration between the public university and the private-owned vaccine company}

We identified two universities actively involved in the MP vaccine development. First, public universities have already established a health-based multi-discipline approach, interinstitutional linkages with the regional hospital, university hospital, and research center for tropical diseases. Second, this public university also has a track record in human and animal vaccine development of new drugs. Moreover, the university hospital is handling infectious diseases research related to vaccine development works. The university also has Biosafety level 3 laboratory facilities (BSL3), reliable scientists, and a global network. Due to the vision similarity in the health sector and innovation, the university decided to cooperate with the private-owned vaccine companies. Second, the private-owned vaccine company is a partner of the public university. As part of a well-established principal company in China that previously focused on animal vaccines, the company is a new entry in human vaccine development. There were two 
vaccine platforms initially developed by the two collaborative actors. Due to the technical issues, the university temporarily ceased the adenovirus vaccine development, whereas the inactivated vaccine already accomplished the 2 nd phase of the preclinical trial in August 2021. Third, the national food and drug agency's role in MP vaccine development. The agency is actively supervising and assisting guidelines and standards implementation among MP developers and companies. During the extensive works and significant progress of vaccine development between the public university and the private-owned vaccine company, the national food and drug agency's role is intensively involved, both upstream and downstream processes in the industry to comply with the GLP and GMP standards. Furthermore, to accelerate the process, the agency has worked beyond the regulatory function of delivering an earlier GLP standard awareness and supervision in R\&D institutes and universities to obtain the proof of concept vaccine candidates. To achieve the EUA during the pandemic, the agency supervises clinical trials under GCP and assists audits of facilities and production methods in the industry.

Figure 5 depicts the triple helix collaboration of Covid-19 between public universities and private-owned vaccine companies. The primary vaccine platform developed by the public university is an inactivated vaccine. The inactivated vaccine is the classical vaccine technology platform. Vaccine, it is necessary to take a disease-carrying virus in an inactivated platform, or something very similar to it, and inactivate using chemicals, heat, or radiation. Researchers have successfully demonstrated the success of this platform in the area of human vaccines on a reasonable scale - for example, influenza and polio vaccines (WHO, 2021b). However, specialized laboratory facilities must cultivate the virus or bacteria safely, require relatively long production times, and will likely require two or three doses-administered vaccines. Moreover, the university has linkage to the university hospital facilities that specialize in treating patients with infectious diseases, which is also possible to access patients with the targeted virus.

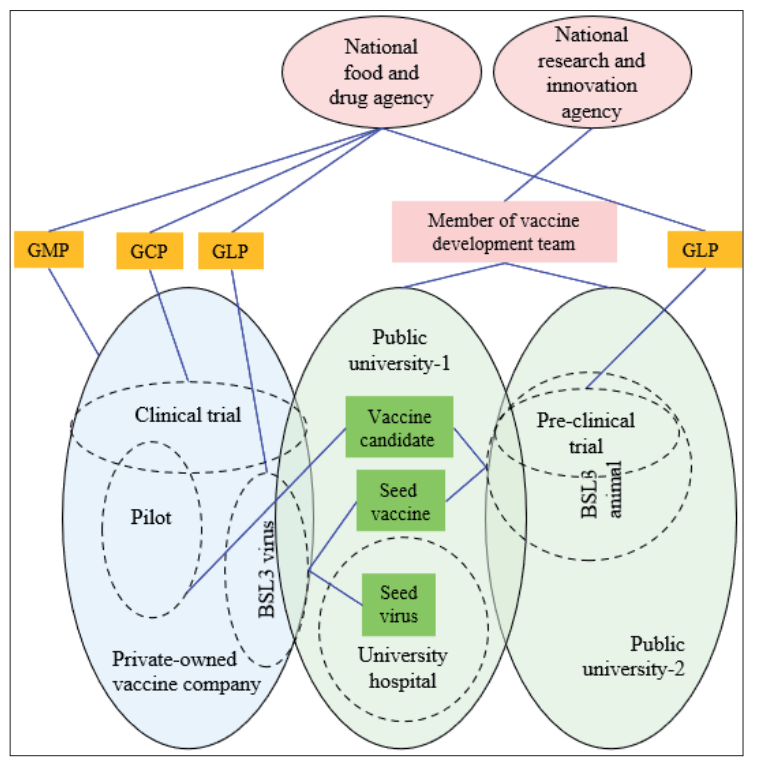

Figure 5. The Triple Helix collaboration of Covid-19 between public universities and the private-owned vaccine company

\section{The Barriers and Enablers}

Based on the roles and functions in Figure 2, the roles and functions of the A-B-G components in the triple helix collaboration, and the data analysis, we determined the barriers and enablers of the Covid-19 vaccine development. Table 1 is a summary of the data analysis. Barriers are factors or conditions that can hamper triple helix collaboration sustainability. Meanwhile, the enablers will encourage the sustainability of the triple helix collaboration. The individual helix should maintain the enablers continuously to meet the proof of concept vaccine candidates requirement, and the company can conduct clinical trials and vaccine mass production to eradicate the pandemic quickly. We identified 4 (four) barriers from the three research institutions related to Indonesia's MP vaccine development, 3 (three) and 2 (two) barriers at the industry and the government sides, respectively. Academics highlight the limited scientists' experiences who will carry out the successful research in vaccines from zero, the real-life of a product research and development project that has a high risk of time and financial loss, technology transfer issues, and lack of knowledge asset. While on the industrial side, issues arise in capitalization and investment policies, markets and commercialization, 
and vaccine efficacy. As a knowledge-intensive product, the vaccine industry is also a capitalintensive industry. From the government's view represented by the national research and innovation agency, the biggest obstacle to the triple helix collaboration of the MP development was vaccine research facilities and infrastructure and policies to accelerate the proof-of-concept vaccines. The vaccine developer highlighted that the government should facilitate BSL3, Animal BSL3, pilot GMP, and the intermediary process before technology transfer to industry. In figure 2, we classified enablers as the roles and functions of the components in the A-B-G triple helix collaboration apart from these nine points.

Table 2 illustrates the barrier and enablers of triple helix collaboration based on the emerging issues approach. In the triple helix collaboration, we categorized barriers and enablers in the following three vital issues: relationships, reputation, and policy. The relationship issues in triple helix collaboration are prevalent in developing countries. It covers communication gaps, industrial relations, and different work cultures between university, industry, and government institutions. The reputation issues can include perceptions of the university's status, R\&D institutions, and capabilities, while the policy issues include developing appropriate policies to integrate knowledge activities, capitalization, and commercialization of products or intellectual property (Razak \& White, 2015).

\section{E. Relationship issue}

The study found that two issues arise from technological and policy formulation issues to accelerate the proof of concept vaccine candidates, as shown in Table 2

\section{1) Technology transfer issue.}

The actors' past experiences strongly determine the technology platform chosen among the available Covid-19 Vaccine platforms. For example, the national institute of bio-molecular research, the state-owned vaccine company partnership, previously developed the Hepatitis B vaccine, a recombinant protein platform. The state-owned vaccine companies also have facilities for producing recombinant proteins, particularly yeast-based processing facilities. Even though the vaccine has not succeeded as proof of concept, the national institute of bio-molecular research also has experience in similar platforms; yeast-based recombinant proteins for the Dengue vaccine. However, in the case of the Covid-19 vaccine, the national institute initiated the seed vaccine so that the technology transfer would take a different path than previous foreign seed vaccines manufactured by the state-owned company. Amidst the hardships and complexity, the collaboration between two actors continues to catch up with the progress. The scientific publication recognizes the ownership of scientific discovery that reflects the primary task of academics, both personal and institutional. However, in the majority of cases, the industry relies on the proof-of-concept criteria. Due to global practice criteria in the vaccine industry, preclinical and comprehensive clinical trials rely strictly on the WHO standards (WHO, 2021c).

\section{2) Policy formulation to increase progress in developing a vaccine candidate.}

Presidential Regulation No. 18 of 2020 stipulates the National Team for Acceleration of the Development of the Corona Virus Disease 2019 (Covid-19) Vaccine. As the agent in charge, the National Research and Innovation Agency has published ministerial decrees; Number $13 / \mathrm{K} /$ KPT/2021 and 15/K/KPT/2021. The national "Merah Putih Vaccine team" is publicly named "Merah Putih Vaccine Consortium," the national technical implementation team.

The main objectives of establishing a national team are: (1) development of a Covid-19 vaccine; (2) realizing the independence of the nation in the development of the Covid-19 vaccine; (3) increasing the synergy of research, development, and application of science and technology, as well as invention and innovation, production, distribution, and use and utilization of the Covid-19 vaccine between the government and science and technology institutions as well as scientific and technological resources in the development of the Covid-19 vaccine; and (4) we can utilize, and increase capacity, as well as national capacity in 
Table 1.

Barrier and enabler for the sustainability of triple helix collaboration in Indonesia (based on the study of Covid-19 vaccine development)

\begin{tabular}{|c|c|c|c|}
\hline & Academic & Industry & Government \\
\hline  & $\begin{array}{l}\text { - } \text { Scientists experiences in vaccine } \\
\text { research and development } \\
\text { - } \text { Real-life research and develop- } \\
\text { ment project } \\
\text { - Technology transfer issues } \\
\text { - Knowledge assets }\end{array}$ & $\begin{array}{l}\text { - Capitalization and investment } \\
\text { policy } \\
\text { - Market and commercialization } \\
\text { - Vaccine efficacy }\end{array}$ & $\begin{array}{l}\text { - R\&D facility and infrastructures. } \\
\text { Policy formulation to accelerate } \\
\text { progress in developing vaccine } \\
\text { candidate proof of concept }\end{array}$ \\
\hline  & $\begin{array}{l}\text { - } \text { Internship } \\
\text { - } \text { Education and training } \\
\text { - } \text { Incubator } \\
\text { - } \text { Spin-off and start-up enterprises } \\
\text { - } \quad \text { R\&D funding } \\
\text { - } \quad \text { international/global network }\end{array}$ & $\begin{array}{l}\text { - } \text { Incentives and tax deduction } \\
\text { - } \quad \text { Production and value-added } \\
\text { - } \quad \text { Entrepreneurial ventures } \\
\text { - } \quad \text { Product life cycle Industrial } \\
\text { strategy } \\
\text { - } \text { Advisory services }\end{array}$ & 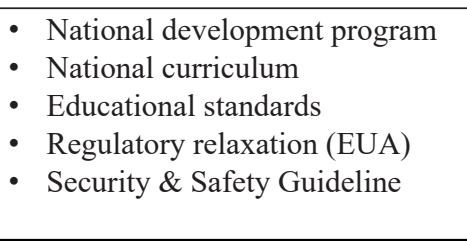 \\
\hline
\end{tabular}

Table 2.

Classification of barrier and enabler for the sustainability of triple helix collaboration with the emerging issues approach.

\begin{tabular}{|c|c|c|c|}
\hline & Relationship Issues & Reputation Issues & Policy Issues \\
\hline 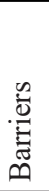 & $\begin{array}{l}\text { - Technology transfer issues } \\
\text { Policy formulation to accelerate } \\
\text { developing the proof of concept } \\
\text { of a vaccine candidate }\end{array}$ & $\begin{array}{l}\text { - Scientist's experiences on a real-life proj- } \\
\text { ect of research and development } \\
\text { - R\&D facility and infrastructure } \\
\text { - Knowledge assets } \\
\text { - Vaccine Efficacy }\end{array}$ & $\begin{array}{l}\text { - Capitalization and investment } \\
\text { policy } \\
\text { - Market and commercialization }\end{array}$ \\
\hline 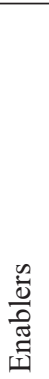 & $\begin{array}{ll}\text { - } & \text { Internship } \\
\text { - } & \text { Education and training }\end{array}$ & $\begin{array}{l}\text { - } \text { Production and value-added } \\
\text { - } \text { Entrepreneurial ventures } \\
\text { - } \text { Product life cycle } \\
\text { - Incubator } \\
\text { - Spin-off and start-up enterprises }\end{array}$ & $\begin{array}{l}\text { - Regulatory relaxation } \\
\text { - Safety, security Guideline } \\
\text { - National development program } \\
\text { - National curriculum } \\
\text { - Educational standards } \\
\text { - Incentives and tax deduction } \\
\text { - R\&D funding } \\
\text { - international/global network } \\
\text { - Industrial strategy } \\
\text { - Advisory services }\end{array}$ \\
\hline
\end{tabular}

vaccine development, as stated in Article 3 of Presidential Regulation Number 18 of 2020.

Both the president and ministerial decrees regulate internal government institutes, including state-owned institutes and universities. However, no detailed mechanism to ensure inter-institutional linkage with industry is unavailable (Leydesdorff, 2018). However, Presidential Decree Number 18 of 2020, presumably as the president's mandate, remains a double helix.

\section{F. Reputation issue}

The study found two dimensions in human resources on research and development projects and $\mathrm{R} \& \mathrm{D}$ facilities and infrastructure, as shown in Table 2.

\section{1) Scientists' experience of a real-life project of research and development.}

According to Leydesdorff \& Fritsch (2006) and Leydesdorff \& Meyer (2003) a triple helix model is a knowledge-based innovative system that attempts to capture the dynamics of communication and organization, introducing the idea of reciprocal exchange in institutional settings. Individuals and institutions have an asset relationship in the form of human resources and all the capabilities possessed by an individual. R \& D institutes have more extensive and structured scientists 
than universities because they work full time and focus on their primary tasks as researchers. In contrast, academics focus on teaching activities and the research activities provided by university students. Due to the skill and safety standard working with the vaccine, a university may select the students who join the vaccine research. In the context of legal protection, an employee and a student are different.

For this reason, several research universities in a developed country have established biotech companies as stand-alone entities. This independent entity is called a spin-off from a research center that was initially under the university. All who work there are employees and not research students. Industrial relations law protects employees and compensates for work accidents or occupational diseases. This company is managed professionally to profitability, contrary to what was done by research centers under the previous university management. Thus, the company can recruit scientists and post-doctoral staff (Cape Bio Pharms, 2021; The Jenner Institute, 2021).

\section{2) $R \& D$ facility and infrastructure.}

$\mathrm{R} \& \mathrm{D}$ facilities and infrastructure are the main issues that the government highlights through the national research and innovation agency. Indeed, in general, the biotech industry, R\&D facilities, and infrastructure must be built by academia or industry. In many cases, a university establishes a biotech company which is then professionally managed like a company. The government-owned facilities and infrastructure will hamper the industry to endeavor capitalization and commercialization efforts. Usually, some developed countries build and use government-owned integrated laboratory facilities for government tasks, such as military purposes (Tran \& Kocaoglu, 2009).

Many biotech companies are research centers that are spin-offs from a university. They are engaged in the development, commercialization of biotech, and technology transfer. They have a focus on expertise and services delivered to related industries. Indeed, it is not easy to establish high-risk business partners such as a vaccine to government R\&D institutes or universities rather than companies. The university is not the right institute for collaboration on high-intensive skill and risk. However, many biotech companies in Europe and America are spin-offs from universities and still carry university identities (Fontes, 2005; The Jenner Institute, 2021).

\section{3) Knowledge assets and vaccine efficacy.}

Knowledge assets are factors that are directly related to scientist experiences. Although biomolecular scientists already have experience developing their vaccines, our national research institutes/universities have not produced vaccines that meet the proof concept criteria. The development of the MP vaccine starts from scratch. Therefore, it needs the support of appropriate government policies to ensure the vaccine meets research standards. Knowledge needs can be met through collaborative research with experienced global partners to produce vaccine innovations that WHO recognizes, with a minimum of $50 \%$ (Geddes, 2021).

\section{G. Policy issue}

Our study found that the following dimensions are arising; capitalization and investment policies and markets and commercialization, as shown in Table 2.

\section{1) Capitalization and investment policy.}

The government should allocate funds directly targeted for the fastest vaccine development and support public-private partnerships to build new vaccine companies rather than state-owned vaccine companies. The national institute of bio-molecular research has lab-scale developed other human vaccines in a recombinant protein vaccine platform, applying a similar platform to the Covid-19 vaccine (MP vaccine). In the case of the EUA vaccine, the state-owned vaccine company has been the registrar for several imported vaccines for the Covid-19 vaccination in Indonesia; inactivated virus platform (Sinovac vaccine), recombinant protein (Astra-Zeneca vaccine), and an RNA platform (Moderna vaccine). In addition, the national food and drug agency has released the EUA for the nationally distributed Moderna and AstraZeneca vaccines in Indonesia due to complying with the 'proof of concept.' 
The challenge for developing the MP vaccine is if the state-owned vaccine company decides to produce all EUA vaccines. State-owned vaccine companies do not need investment if they only produce vaccines that have proof of concept, but this is not the case if they produce vaccines that are not yet proof of concept. The national institute of bio-molecular, state-owned vaccine companies will require significant investments.

\section{2) Market and competition.}

Indonesia is the biggest market (4th most populous globally) based on the population's needs requiring vaccines. To date, only imported vaccines are available domestically. In addition, more countries need vaccines, especially those that rely on imported vaccines. Covid-19 is an international program that WHO vaccinates through the framework of the COVAX facility. From a market perspective, there is no doubt that state-owned vaccine companies will produce vaccines if all vaccines are proof of concept. The main objectives of state-owned vaccine companies are: (1) obtaining WHO approval, so COVAX will provide all vaccine facilities; (2) The Ministry of Health distributes all vaccinations through a national vaccination program with the approval of the Food and Drug Supervisory Agency; (3) approval from the other national FDA of all vaccines then Ministry of Health vaccination programs will establish selected countries to distribute the vaccines. To create a commercial the state-owned vaccine company is always looking for the proof of concept seed vaccines or "ready to fill" vaccines to ensure the stock of national vaccines. The one obstacle for state-owned vaccine companies is when local vaccine seeds require imported auxiliary materials, usually prepared by global players such as the UK, US, Russia, and China (Bio Farma, 2021).

Market competition in fulfilling vaccines is more on exploring and inventing vaccine seeds that are quality, safe, efficacious, and require low production costs (Rappuoli \& Hanon, 2018). The proof of those four criteria is carried out scientifically through WHO publications, although the use for Covid-19 vaccination requires EUA approval by each country. The development of a Covid-19 vaccine does not stop with the EUA alone. WHO has opened an emergency use list (EUL) procedure, a form of a report on vaccine development after using an emergency for vaccination. Clinical trials are carried out continuously and refined and reported. EUL is a form of global information in recognition of the quality, safety, and efficacy of the Covid-19 vaccine. The EUL is the real competition in the development of the Covid-19 vaccine. WHO has stated that EUL is a prerequisite for COVAX vaccine supply (WHO, 2021c).

Nonetheless, during a pandemic, all countries under WHO agreed to ensure fair and equitable access to vaccines and ensure every country receives them and can roll them out to protect their people, starting with the most vulnerable. Because vaccines are not what will stop the pandemic, but vaccinations (WHO, 2021a).

\section{H. From enablers to sustainability}

The results in the barrier analysis showed that the most highlighted issue is reputation; (1) scientists' experience or R\&D human resources on real-life projects, and (2) R\&D facilities and infrastructure (3) knowledge asset and vaccine efficacy. However, neither of the issues can accelerate the proof-of-concept vaccine candidate immediately. The government's support for integrated lab vaccine facilities and infrastructures is urgently needed to ensure the sustainability of the triple helix collaboration of the Covid-19 vaccine development. The rationale appears as follows: (1) it takes a long-term to establish readily integrated lab facilities and infrastructures; (2) the ultimate goal of MP vaccine development is to reduce imported vaccines that are harmful to the national stock vaccine and anticipate the future pandemic so the term "MP vaccine' should be extended. (3) The concept "Merah Putih vaccine " should be considered to engage the global player. Besides developing the local-transmitted genetic materials, Indonesia should establish the grand design and allow the global partners to accomplish the essential vaccine testing and unavailable access facilities in Indonesia. (3) The industry openly collaborates with global R\&D institutes and universities to set the appropriate technology transfer. However, the global players' 
role is essential in the context of the MP vaccine development. The triple helix does not only have national boundaries in innovating. Due to the scope of cooperation between countries being part of the global triple helix, innovation initiation and processes are globally interconnected ( $\mathrm{J}$. Liu et al., 2013).

Configuration between the national institute of bio-molecular research and state-owned company vaccine has demonstrated triple helix collaboration. The configuration performs a none or weaker linkage than public university - the private-owned vaccine company collaboration. On the other hand, the public university - the private-owned vaccine company performed a more vital linkage, while the government role is none or weaker.

Figure 7 displays the comparison of the triple helix configuration between the two partnerships. First, the collaboration between national biomolecular research institutes and the state-owned vaccine industry is less than the public university and private-owned vaccine company partnership. The National Institute of Biomolecular Research is highly dependent on the government and not resource-independent and faces bureaucracy gaps. For example, the bureaucracy gap might come from the lab facilities' procurement process and mechanism. In addition, the operations of this R\&D institution must be in line with the duties and functions of a government research institution. The R\&D institute cannot stand alone based on the logic (capitalization, commercialization, employees, politics).

Thus, to establish a balanced triple helix cooperation arrangement, this $R \& D$ institute is constrained by human resources unless it represents a spin-off from the government R\&D. Meanwhile, its industrial partner, the state-owned vaccine industry, collaborates with several global $\mathrm{R} \& \mathrm{D}$ institutes and universities.

As a profit entity, the company may prefer to seek a low-risk, experienced global institute(s), which is already proof-of-concept for the vaccine seed. Second, it seems a more vital linkage and collaboration between a public university and a private vaccine company.

The university is government-resource independent. The independence of the public university is due to the autonomous entity like industry. Based on the institutional logic, in terms of capitalization, commercialization, employees, politics, the government can foster academic-industrial collaboration with policies that strengthen a triple helix configuration. One of these is encouraging universities to spin-off institutions that carry out bio-molecular research to be more professional and profitable while still bringing out the university's excellence (Cape Bio Pharms, 2021; The Jenner Institute, 2021).

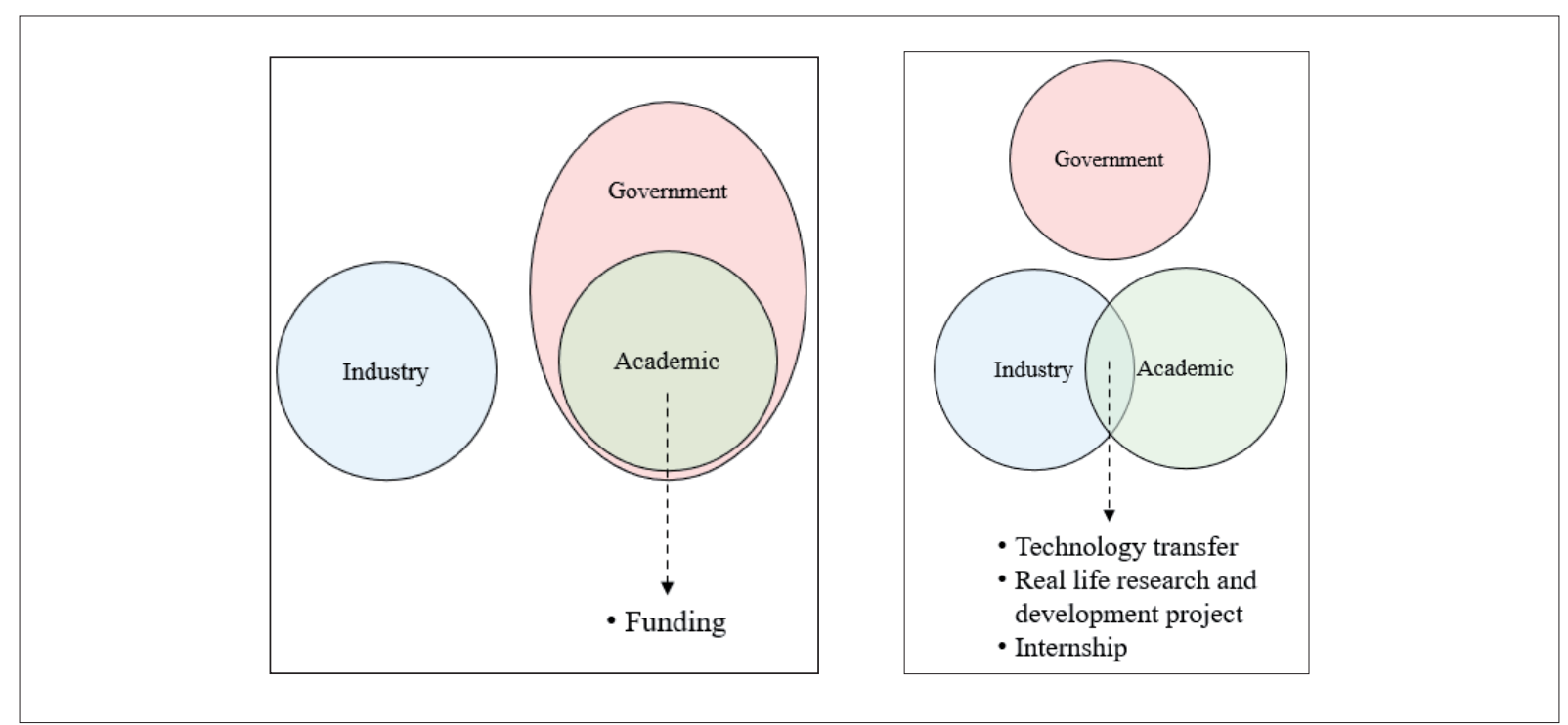

Figure 6. Comparison between two triple helix configurations in Covid-19 vaccine development. The National Institute of bio-molecular research - state-owned vaccine company collaboration (left). The public universityprivate-owned vaccine company collaboration (right) 


\section{CONCLUSION}

The development of vaccines with a pandemic paradigm requires global collaboration, transcending national borders to obtain a local vaccine that reduces the burden on countries. It also addresses the need for vaccines in many countries. Our finding of the triple helix collaboration analysis showed that the linkage among actors (industry-academics-government) refers to Presidential Decree (KEPRES) No. 18 of 2020 concerning the National Team for Acceleration of Vaccine Development for Corona Virus Disease 2019 (Covid-19) is not optimal. The primary indicator is that no seed vaccine or vaccine candidate has met or is close to the proof-of-concept criteria. Compared to the issues arising from triple helix collaboration in developing countries, less-experienced scientists and vaccine research infrastructure are the two main factors.

In contrast, the national vaccine industry has the adequate capacity to produce proof-of-concept vaccines. We distinguished the Triple Helix configuration involving two prominent partnerships, namely the national institute of bio-molecular research-the state-owned vaccine company and the public university-private-owned vaccine company based on the linkage of the components. The first partnership currently tends to be more limited due to bureaucratic obstacles, especially in the A-helix at The national institute of biomolecular research, which causes barriers that might impact vaccine development performance which is relatively less dynamic than the second partnership (the public university-the private vaccine company). The barriers experienced by the first partnership are illustrated by the configuration of the triple helix collaboration, which tends to be static and less flexible, controlled by the government because it is part of a governmentowned institution. The configuration of the triple helix collaboration for a public university-private vaccine company is relatively more independent, less regulated by the government (in this case, by the national research and innovation agency). Meanwhile, the role of the food and drug supervision agency, as part of the G-Helix component, plays a vital role, especially in mentoring activities to meet regulatory requirements from upstream to downstream processes, especially for efficacy and safety. The more advanced the stages of vaccine development, the more intense the role of the food and drug supervision agency.

Policy Implication of the research would be related to the government's tasks in providing policies that allow academia and industry to collaborate more freely. Currently, the institution collaborates on its initiative and relies on its respective global network of partners to support the vaccine development process to fulfill national vaccination programs and global supply. In the short term, the government must facilitate the MP vaccine development in collaboration with international partners who have adequate vaccine research and development infrastructure. This collaboration has been carried out, especially with parties/potential partners who have successful experience in developing Covid-19 vaccines. For the long-term target, Indonesia will build its vaccine research and development infrastructure, which can also function as an intermediary process prior to transferring technology from universities/R\&D institutes to industry. However, the research and innovation agency should manage the open and integrated vaccine lab facilities and infrastructure professionally and profitably.

\section{ACKNOWLEDGMENT}

We express our gratitude to the Deputy Chairman of Scientific Services, Indonesian Institute of Sciences (LIPI) for providing the research funding in 2021. We are indebted to Dr. Sonni Yuliar for his contribution to improving this paper and making this paper eligible for publication.

\section{REFERENCES}

Allanson, P., \& Montagna, C. (2005). Multiproduct firms and market structure: An explorative application to the product life cycle. International Journal of Industrial Organization, 23(7-8). https://doi.org/10.1016/j.ijindorg.2005.02.001

Bio Farma. (2019). 2019 Annual Report of Bio Farma. Retrieved from https://www.biofarma.co.id/en/ annual-report. Download on 10-15-2021.

Bio Farma. (2021). 50th Delivery of Covid-19 Vaccine Arrives at Bio Farma: Covid-19 Vaccine Supply is Safe Covid-19 Vaccine Distribution Continues. Retrieved from https://www.biofarma.co.id/en/latest-news/ 
detail/50th-delivery-of-covid19-vaccinearrives-at-bio-farma-covid19-vaccine-supplyis-safe-covid19-vaccine-distribution-continues. Download on 10-15-2021.

Bloom, D. E., Cadarette, D., Ferranna, M., Hyer, R. N., \& Tortorice, D. L. (2021). How New Models Of Vaccine Development For COVID-19 Have Helped Address An Epic Public Health Crisis. Health Affairs, 40(3). https://doi.org/10.1377/ hlthaff.2020.02012

Cai, Y. (2013). Enhancing context sensitivity of the Triple Helix model: An institutional logics perspective. The Triple Helix XI International Conference, 1-30. https://www.triplehelixconference.org/th/11/bic/docs/Papers/Cai.pdf

Cai, Y., \& Etzkowitz, H. (2020). Theorizing the Triple Helix model: Past, present, and future. Triple Helix Journal. https://doi. org/10.1163/21971927-bja10003

Cai, Y., \& Liu, C. (2015). The roles of universities in fostering knowledge-intensive clusters in Chinese regional innovation systems. Science and Public Policy, 42(1). https://doi.org/10.1093/ scipol/scu018

Cai, Y., Ramis Ferrer, B., \& Luis Martinez Lastra, J. (2019). Building University-Industry CoInnovation Networks in Transnational Innovation Ecosystems: Towards a Transdisciplinary Approach of Integrating Social Sciences and Artificial Intelligence. Sustainability, 11(17). https://doi.org/10.3390/su11174633

Cape Bio Pharms. (2021). Our Story. Retrieved from http://www.capebiopharms.com/about/OurStory. Download on 10-15-2021.

Chung, C. (2013). Government, policy-making and the development of innovation system: The cases of Taiwanese pharmaceutical biotechnology policies (2000-2008). Research Policy, 42(5). https://doi.org/10.1016/j.respol.2013.01.007

Collins, A. (1998). National Science Education Standards: A political document. Journal of Research in Science Teaching, 35(7). https://doi.org/10.1002/ (SICI) 1098-2736(199809)35:7<711::AIDTEA3>3.0.CO;2-O

Collinson, S., \& Liu, Y. (2019). Recombination for innovation: performance outcomes from international partnerships in China. $R \& D$ Management, 49(1). https://doi.org/10.1111/ radm. 12293

Conceicao, P., \& Heitor, M. v. (1999). On the role of the university in the knowledge economy. Science and Public Policy, 26(1). https://doi. org/10.3152/147154399781782617
Contractor, F. J., \& Lorange, P. (2002). The growth of alliances in the knowledge-based economy. International Business Review, 11(4). https:// doi.org/10.1016/S0969-5931(02)00021-5

Detmer, D. E. (2003). Building the national health information infrastructure for personal health, health care services, public health, and research. BMC Medical Informatics and Decision Making, 3(1). https://doi.org/10.1186/1472-6947$3-1$

Druedahl, L. C., Minssen, T., \& Nicholson Price, W. (2021). Collaboration in Times of Crisis: A Study on COVID-19 Vaccine R\&amp;D Partnerships. Vaccine. https://doi.org/10.1016/j. vaccine.2021.08.101

Eisenhardt, K. M., \& Graebner, M. E. (2007). Theory Building From Cases: Opportunities And Challenges. Academy of Management Journal, 50(1). https://doi.org/10.5465/ amj.2007.24160888

Etzkowitz, H. (2008). The Triple Helix. Routledge. https://doi.org/10.4324/9780203929605

Etzkowitz, H., \& Leydesdorff, L. (1997). Introduction to special issue on science policy dimensions of the Triple Helix of university-industrygovernment relations. Science and Public Policy. https://doi.org/10.1093/spp/24.1.2

Etzkowitz, H., \& Leydesdorff, L. (2000). The dynamics of innovation: from National Systems and "Mode 2" to a Triple Helix of university-industry-government relations. Research Policy, 29(2). https://doi.org/10.1016/ S0048-7333(99)00055-4

Etzkowitz, H., \& Zhou, C. (2018). Innovation incommensurability and the science park. $R \& D$ Management, 48(1). https://doi.org/10.1111/ radm. 12266

Fontes, M. (2005). The process of transformation of scientific and technological knowledge into economic value conducted by biotechnology spin-offs. Technovation, 25(4). https://doi. org/10.1016/j.technovation.2003.08.004

Geddes, L. (2021). How effective are COVID-19 vaccines in the real-world? GAVI. Retrieved from https://www.gavi.org/vaccineswork/howeffective-are-covid-19-vaccines-real-world. Download on 10-15-2021.

Guimón, J., \& Narula, R. (2020). Ending the COVID-19 Pandemic Requires More International Collaboration. Research-Technology Management, 63(5). https://doi.org/10.1080/0895630 8.2020 .1790239 
Hishida, K. (2013). Fulfilling the Promise of Technology Transfer (K. Hishida, Ed.). Springer Japan. https://doi.org/10.1007/978-4-431-54306-0

James, T. E., \& Jorgensen, P. D. (2009). Policy Knowledge, Policy Formulation, and Change: Revisiting a Foundational Question. Policy Studies Journal, 37(1). https://doi.org/10.1111/j.15410072.2008.00300.x

Jørgensen, H. D. (2004). Interactive Process Models. (Doctoral thesis, Norwegian University of Science and Technology, Norway)

Knudson, W., Wysocki, A., Champagne, J., \& Peterson, H. C. (2004). Entrepreneurship and Innovation in the Agri-Food System. In Source: American Journal of Agricultural Economics (Vol. 86, Issue 5). https://www.jstor.org/stable/3697949

Konstantinovich, K., Alekseevna, K., Viktorovna, D., \& Vladimirovich, S. (2021). The modern outline of the "triple helix" system: generating ideas in the fight against the pandemic. Journal of Complementary Medicine Research, 12(1). https://doi.org/10.5455/jcmr.2021.12.01.20

Kreusel, N., Roth, N., \& Brem, A. (2018). European business venturing in times of digitisation - an analysis of for-profit business incubators in a triple helix context. International Journal of Technology Management, 76(1/2). https://doi. org/10.1504/IJTM.2018.088707

Krippendorff, K. (1989). Product Semantics: A Triangulation and Four Design Theories. http:// repository.upenn.edu/asc_papers/254

Kumari, M., \& Mallick, S. (2017). Triple Helix Model of Innovation and the Politics of Genetically Modified Crops: Cases of Bt Cotton and Bt Brinjal in India. Perspectives on Global Development and Technology, 16(4). https:// doi.org/10.1163/15691497-12341443

Langley, A. (1999). Strategies for Theorizing from Process Data. Academy of Management Review, 24(4). https://doi.org/10.5465/ amr.1999.2553248

Leydesdorff, L. (2000). The triple helix: an evolutionary model of innovations. Research Policy, 29(2). https://doi.org/10.1016/S00487333(99)00063-3

Leydesdorff, L. (2018). Synergy in Knowledge-Based Innovation Systems at National and Regional Levels: The Triple-Helix Model and the Fourth Industrial Revolution. Journal of Open Innovation: Technology, Market, and Complexity, 4(2). https://doi.org/10.3390/joitmc4020016
Leydesdorff, L., \& Fritsch, M. (2006). Measuring the knowledge base of regional innovation systems in Germany in terms of a Triple Helix dynamics. Research Policy, 35(10). https://doi. org/10.1016/j.respol.2006.09.027

Leydesdorff, L., \& Meyer, M. (2003). The Triple Helix of university-industry-government relations. Scientometrics, 58(2). https://doi. org/10.1023/A:1026276308287

Liu, C., \& Cai, Y. (2018). Triple Helix Model and Institutional Logics in Shenzhen Special Economic Zone. Science and Public Policy, 45(2). https://doi.org/10.1093/scipol/scx059

Liu, J., Chaminade, C., \& Asheim, B. (2013). The Geography and Structure of Global Innovation Networks: A Knowledge Base Perspective. European Planning Studies, 21(9). https://doi. org/10.1080/09654313.2012.755842

Lurie, N., Saville, M., Hatchett, R., \& Halton, J. (2020). Developing Covid-19 Vaccines at Pandemic Speed. New England Journal of Medicine, 382(21). https://doi.org/10.1056/ NEJMp2005630

Mian, S. A. (1996). The university business incubator: A strategy for developing new research/ technology-based firms. The Journal of High Technology Management Research, 7(2). https://doi.org/10.1016/S1047-8310(96)900048

Monsreal-Barrera, M. M., Cruz-Mejia, O., Ozkul, S., \& Saucedo-Martínez, J. A. (2020). An optimization model for investment in technology and government regulation. Wireless Networks, 26(7). https://doi.org/10.1007/s11276-01901958-z

Moretti, F., van Vliet, L., Bensing, J., Deledda, G., Mazzi, M., Rimondini, M., Zimmermann, C., \& Fletcher, I. (2011). A standardized approach to qualitative content analysis of focus group discussions from different countries. Patient Education and Counseling, 82(3). https://doi. org/10.1016/j.pec.2011.01.005

Nurhakim, F. (2021). Indonesia Tidak Berpengalaman Buat Vaksin COVID-19. Retrieved from https:// www.gatra.com/detail/news/509049/kesehatan/ indonesia-tidak-berpengalaman-buat-vaksincovid-19. Download on 10-15-2021.

O’Sullivan, E., Andreoni, A., Lopez-Gomez, C., \& Gregory, M. (2013). What is new in the new industrial policy? A manufacturing systems perspective. Oxford Review of Economic Policy, 29(2). https://doi.org/10.1093/oxrep/ grt027 
Ranga, M., \& Etzkowitz, H. (2013). Triple Helix Systems: An Analytical Framework for Innovation Policy and Practice in the Knowledge Society. Industry and Higher Education, 27(4). https:// doi.org/10.5367/ihe.2013.0165

Rappuoli, R., \& Hanon, E. (2018). Sustainable vaccine development: a vaccine manufacturer's perspective. Current Opinion in Immunology, 53. https://doi.org/10.1016/j.coi.2018.04.019

Razak, A. A., \& White, G. R. T. (2015). The Triple Helix model for innovation: a holistic exploration of barriers and enablers. International Journal of Business Performance and Supply Chain Modelling, 7(3). https://doi.org/10.1504/ IJBPSCM.2015.071600

Saad, M., \& Zawdie, G. (2011). Introduction to special issue: The emerging role of universities in socio-economic development through knowledge networking. Science and Public Policy, 38(1). https://doi.org/10.3152/030234 211X12960315267453

Schramm, L. (2017). An Innovation Technology: A Dictionary. In Innovation Technology. De Gruyter. https://doi.org/10.1515/9783110429176-002

Slaughter, S., \& Rhoades, G. (1996). The Emergence of a Competitiveness Research and Development Policy Coalition and the Commercialization of Academic Science and Technology. Science, Technology, \& Human Values, 21(3). https:// doi.org/10.1177/016224399602100303

Solesvik, M. Z. (2017). The triple helix model for regional development and innovation: Context of nordic countries. Forum Scientiae Oeconomia, 5(4), 5-21. https://doi.org/10.23762/ FSO_VOL5NO4_17_1

Szeinbach, S. L., Barnes, J. H., \& Garner, D. D. (1997). Use of pharmaceutical manufacturers' value-added services to build customer loyalty. Journal of Business Research, 40(3). https:// doi.org/10.1016/S0148-2963(96)00239-1

The Jenner Institute. (2021, October 10). People. Retrieved from https://www.jenner.ac.uk/Team. Download on 10-15-2021.

Tran, T. A., \& Kocaoglu, D. F. (2009, August). Literature review on technology transfer from government laboratories to industry. PICMET '09 - 2009 Portland International Conference on Management of Engineering \& Technology. https://doi.org/10.1109/PICMET.2009.5261800

Veselá, D., \& Klimová, K. (2014). Knowledge-based Economy vs. Creative Economy. Procedia Social and Behavioral Sciences, 141. https:// doi.org/10.1016/j.sbspro.2014.05.072

Viale, R. (2013). Knowledge Driven Capitalization of Knowledge Capitalization of knowledge. In Methodological Cognitivism. Springer Berlin Heidelberg. https://doi.org/10.1007/978-3-64240216-6_14

WHO. (2021a). COVID-19 vaccines. Retrieved from Https:/Www.Who.Int/Emergencies/Diseases/ Novel-Coronavirus-2019/Covid-19-Vaccines. Download on 10-15-2021.

WHO. (2021b). The different types of COVID-19 vaccines. WHO's Vaccines Explained Series. Retrieved from https://www.who.int/newsroom/feature-stories/detail/the-race-for-acovid-19-vaccine-explained. Download on 10-15-2021.

WHO. (2021c). COVID-19 vaccine tracker and landscape. Retrieved from https://www.who. int/publications/m/item/draft-landscape-ofcovid-19-candidate-vaccines. Downloaded on 10-15-2021.

Yang, P. Y., \& Chang, Y. -C. (2010). Academic research commercialization and knowledge production and diffusion: the moderating effects of entrepreneurial commitment. Scientometrics, 83(2). https://doi.org/10.1007/s11192-009-0075-1

Yoda, N., \& Kuwashima, K. (2020). Triple Helix of University-Industry-Government Relations in Japan: Transitions of Collaborations and Interactions. Journal of the Knowledge Economy, 11(3). https://doi.org/10.1007/s13132-01900595-3

Yoon, J., \& Park, H. W. (2017). Triple helix dynamics of South Korea's innovation system: a network analysis of inter-regional technological collaborations. Quality \& Quantity, 51(3). https:// doi.org/10.1007/s11135-016-0346-X 